
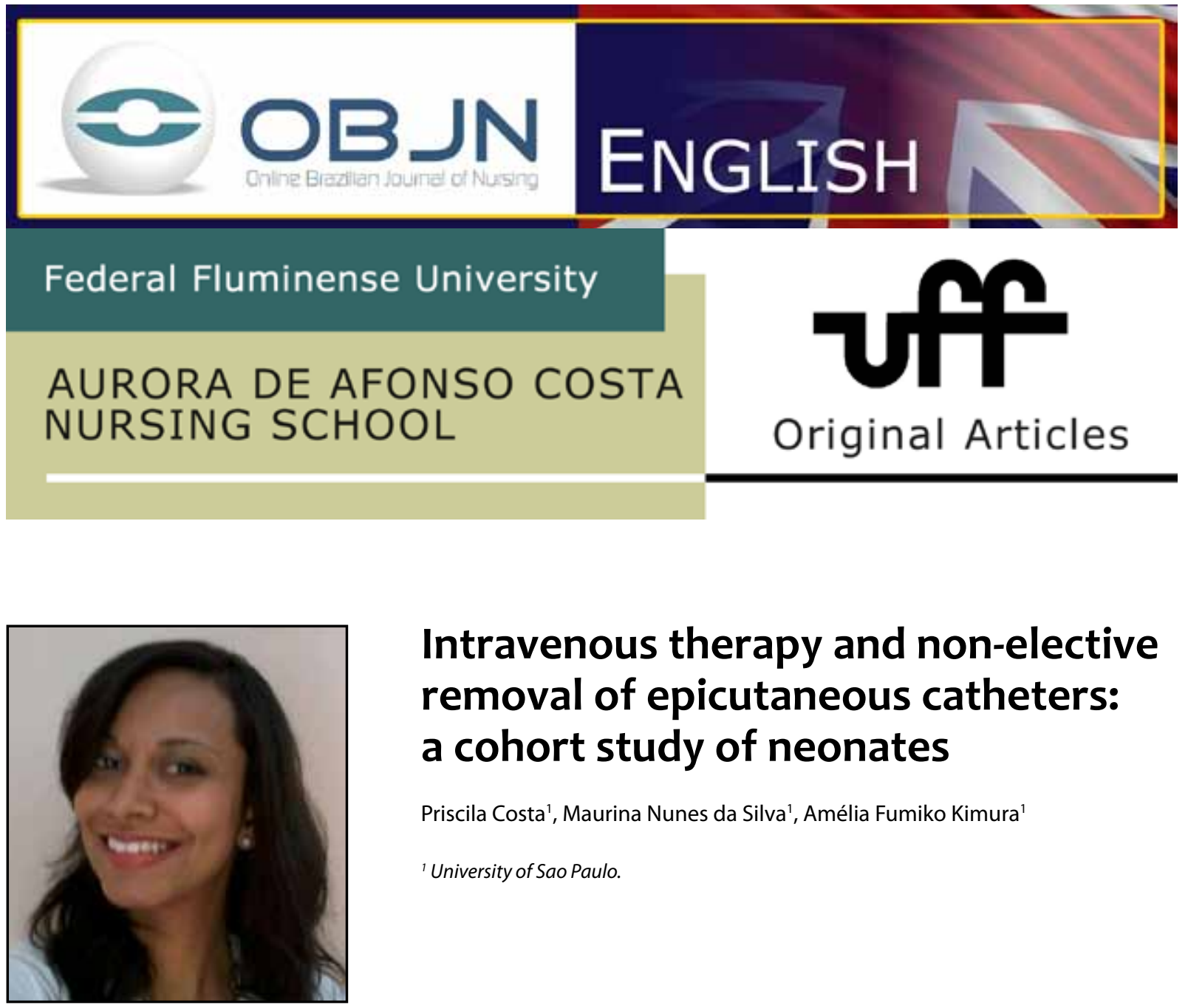

\title{
Intravenous therapy and non-elective removal of epicutaneous catheters: a cohort study of neonates
}

\author{
Priscila Costa ${ }^{1}$, Maurina Nunes da Silva' ${ }^{1}$ Amélia Fumiko Kimura' ${ }^{1}$ \\ ${ }^{1}$ University of Sao Paulo.
}

\begin{abstract}
Aim: To investigate the association between intravenous therapy and the incidence of non-elective removal of silicone single-lumen catheters installed in newborns. Method: this was a prospective cohort study, conducted in a neonatal intensive care unit of a private hospital of São Paulo. The sample was composed of 97 epicutaneous catheters, 15 of them used for single intravenous therapy and 82 indicated for multiple intravenous therapy. Results: The incidence of non-elective removal was $26.7 \%$ in single infusate catheters and $36.5 \%$ in multiple intravenous infusion catheters, with no statistically significant difference being noted ( $p=0.33$ ). Complications such as limb edema and extravasation occurred only in multiple IV infusion catheters. Conclusion:We recommend the adoption of strategies for prevention, early detection and prompt treatment of complications that result in non-elective removal of epicutaneous catheters, regardless the intravenous therapy type.
\end{abstract}

Descriptors: Central venous catheterization; Critical care; Infant, Newborn; Neonatal nursing. 


\section{INTRODUCTION}

Ensuring safe venous access in neonates is a constant challenge in the work routine of the nursing team. Nurses have to select the vascular device that best matches the prescribed intravenous therapy, its expected duration, the integrity of the patient's vascular system, their own professional skill and the resources available for the caring of the device ${ }^{(1)}$.

A peripherally inserted central catheter (PICC) or epicutaneous catheter is one of the options for vascular access in neonates, because it is a non-tunneled central vascular device inserted bedside using an aseptic technique, through a peripheral vein of a upper or lower limb ${ }^{(2)}$. These catheters are indicated for short or long term use, for intermittent or continuous intravenous infusion solutions such as antineoplastic medicine, drugs with vesicant or irritant characteristics, parenteral nutrition and a variety of antibiotics and other drugs with a $\mathrm{pH}$ of less than 5 or more than 9 , as well as solutions with higher than $600 \mathrm{mOsm} / \mathrm{L}$ osmolarity ${ }^{(1,3)}$.

The Brazilian Federal Council of Nursing and Nursing Regional Council of São Paulo state consider the insertion, maintenance and removal of PICC as a competence exclusive to nurses with specific expertise, scientific know-how and knowledge regarding the regulatory requirements and ethical principles associated with safe practice ${ }^{(4,5)}$.

The PICC used in the neonatal population has a diameter of 1.1 to 3.0 French $(\mathrm{Fr})$, is produced with biocompatible material such as silicone and polyurethane, single and double lumen, and may or may not contain an anti-reflux valve at its distal end ${ }^{(1,2)}$. The epicutaneous single lumen catheter is indicated for the infusion of an exclusive intravenous therapy type, such as parenteral nutrition or antibiotics. The double lumen catheter is indicated for infants who receive multiple simultaneous infusions ${ }^{(2)}$ such as general intravascular access and vasoactive drugs. However, the double lumen catheter is still a new technology, the use of which is increasing in the clinical setting, so its availability in health services is still limited.

Studies show that the epicutaneous catheter predominantly used in the neonatal population is single-lumen, made of silicone and of a 1.9 Fr gauge ${ }^{(6)}$. This is a catheter that has been used in Brazilian neonatal intensive care units (NICU) since the 1990 s $^{(7)}$. Considering that it is not always possible to adjust the catheter type to the prescribed IV therapy, it is common to use a single-lumen PICC to allow multiple solutions infusion. However, the type of IV therapy may influence the occurrence of complications that lead to non-elective removal of the catheter ${ }^{(2)}$.

The most common complications that lead to the non-elective removal of the PICC in neonates and children include the mechanics, such as obstruction, accidental pull, rupture and leakage of catheter, as well as infectious complications, phlebitis and thrombosis ${ }^{(8)}$. A cohort study conducted at a NICU in São Paulo analyzed 270 PICCs and reported an incidence of non-elective removal in $35.4 \%$ of cases, and an incidence rate of 34.8 / 1000 catheters-day, for the 1.9 Fr silicone catheter and the most frequent complications were external rupturing and obstruction ${ }^{(9)}$. The obstruction may be thrombotic or non-thrombotic; non-thrombotic blockages are caused by the precipitation of incompatible drugs and multiple infusions through the catheter lumen, and the thrombotic blockage by clots ${ }^{(8)}$.

Nursing care plays a crucial role in preventing complications related to the use of PICC in neonates. The literature suggests that the type of intravenous therapy may be associated 
with the occurrence of complications in the use of epicutaneous catheters, according to results of a study that analyzed 67 neonates who underwent 84 PICC single silicone lumen and double lumen polyurethane catheter insertions. This research demonstrated that, of the catheters non-electively removed, $27.3 \%$ were indicated for infusion of only one type of intravenous solution and $72.7 \%$ were referred for the infusion of multiple intravenous solutions ${ }^{(6)}$. Thus, the proposed hypothesis of this study is that the single lumen 1.9Fr gauge silicone catheters that have been nominated for multiple IV therapy have a higher incidence of non-elective removal when compared to catheters indicated for single intravenous therapy.

Studies on the association between the type of IV therapy (single or multiple) which indicated the insertion of PICC, and the occurrence of the non-elective removal of the catheter due to complications, are scarce ${ }^{(6)}$. Consequently, there is a need for studies in neonates comparing the incidence of complications that led to the non-elective removal of the PICC according to the prescribed intravenous therapy.

Considering that the nurse plays a central role in the insertion, maintenance and removal of epicutaneous catheters as well as in the prevention, identification, and treatment of complications from the procedure, we justify the need to carry out this study which aims to determine the association between the type of intravenous therapy and the incidence of non-elective removal of single lumen catheters installed in a cohort of newborns.

\section{METHOD}

This is a cohort study with prospective data collection, conducted in the NICU of a large private hospital in São Paulo. The NICU has 60 beds and the workforce consists of 24 nurses, 18 of whom are qualified for the insertion, maintenance and removal of the PICC. In accordance with Resolution 466/12 of the National Health Council, the research project was submitted and approval for data collection was granted by the Ethics Committee of the hospital (Case No. 238/2010).

The use of PICC in this institution follows the guidelines defined in the protocol designed by the nurses in the venous catheters' study group, based on rules established by professional societies that qualify Brazilian nurses to manage PICCs. At the institution where data were collected, the insertion and removal of the PICC is a medical assignment. The installation of the catheter is an aseptic procedure performed at the bedside by qualified nurses, after review of the clinical condition and venous network of the newborn.

The study subjects were selected from a daily control performed by the NICU nurses regarding the type of vascular device installed on each newborn admitted during the period from August $31^{\text {st }}, 2010$ to February $10^{\text {th }}, 2011$. The following were considered as criteria for eligibility: neonates without congenital diseases, born in hospital maternity units and who underwent the insertion of silicone $1.9 \mathrm{Fr}$ single-lumen PICC during the NICU treatment period. We excluded from study those patients who did not have medical records about the vascular device being used or description of the intravenous solution infused at the time of installation of the catheter, ones without date or reason for the removal of the device, and patients who died or were transferred during the use of PICC.

To calculate the sample size, we used the findings of an earlier cross-sectional study conducted with 67 newborns undergoing 
insertion of the PICC in the NICU of the institution associated with this research ${ }^{(6)}$. We adopted a significance level (a) of $5 \%$, power ( $\beta$ ) of $80 \%$. In this study, of the catheters that were non-electively removed, $72.7 \%$ were used for multiple intravenous therapy, and $27.3 \%$ had only one type of intravenous solution, i.e., a ratio of 3:1 (three PICCs with multiple intravenous catheters for each single IV infusion) in a two-tail test. Thus, we estimated a sample of 15 PICCs for the group with single intravenous therapy and 45 PICCs for the group with multiple IV therapy. Data were collected until the number of silicone PICCs with a single type of intravenous solution was reached, resulting in a final sample of 97 PICCs, 15 with single intravenous infusion and 82 with multiple IV therapy.

Data were extracted from patient records and from an institutional form entitled PICC control form, in which the nursing staff records information related to the insertion, maintenance and removal of the device. With regard to the recording of data we used a standard form containing the variables of interest in the study: clinical diagnosis, gender, postnatal age, gestational age and weight at the time of the procedure, the epicutaneous catheter used (material, gauge and number of lumens), the insertion segment of the catheter tip position (central or non-central), the IV therapy which indicated insertion (parenteral nutrition, serum, antibiotics, antifungal, vasoactive drugs) at the time of catheter insertion, the duration of catheter use, and the date and reason for removal.

We considered intravenous therapy the solution administered intravenously. The IV therapy that indicated catheter insertion was classified as single or multiple infusion. The single infusion relates to the indication of the PICC for the infusion of only one intravenous solution, for example, parenteral nutrition. Multiple infusion concerns the indication of catheter use on the prescription of more than one type of intravenous solution, such as parenteral nutrition and antibiotics or serum therapy, vasoactive drugs and antimicrobials.

We considered elective removal of the PICC to be what occurred due to the end of IV therapy or due to the prescription of solutions compatible with peripheral administration. Defined as non-elective catheter removal were the ones motivated by complications such as obstruction, rupture, migration of the tip, phlebitis, thrombosis, catheter-related infection, edema, infiltration, extravasation and accidental pulling of the catheter.

The collected data were stored in a Microsoft Office Excel 2010 spreadsheet and analyzed using Epi-Info 3.5.1 software. Continuous variables were analyzed using descriptive statistics, and categorical ones via absolute and relative frequencies. For categorical variables, the existence of differences between the groups with and without multiple infusion was determined by chi-square or Fisher's exact tests, and estimation of relative risk and confidence interval of 95\%. For continuous variables, the Student $t$ test was used. The level of significance was $p \leq 0.05$ with a $95 \%$ confidence interval.

\section{RESULTS}

During the period of data collection the installation of epicutaneous catheters in the NICU was monitored daily in order to identify eligible catheters to the sample of the present study, as shown in Figure 1. Finally, 97 catheters were included in the sample; 15 of these were indicated for single infusate and 82 for multiple IV therapy. 
Flowchart 1: Eligibility of the catheters installed in the cohort of neonates. São Paulo, 2010-2011

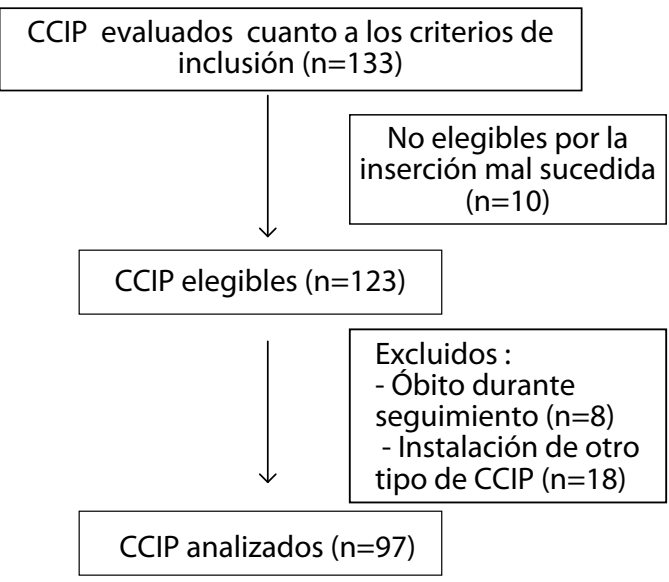

The 97 catheters were installed in 82 newborns, and most of the neonates underwent only one catheterization $(71 ; 86.6 \%)$. The remaining newborns (13.4\%) received between two to five catheters during their hospitalization. The neonates in the two groups, i.e., those with multiple intravenous therapy and those with single infusion were compared regarding their clinical and demographic characteristics in order to check if the groups are homogeneous and can be compared regarding their primary outcomes (Table 1).

The population of neonates was characterized as being predominantly male, 59 (60.8\%), either among neonates with indication of PICC for multiple infusion or among those with single infusion, with no statistically significant difference between groups ( $p=0.94)$. The most common clinical diagnosis in the studied population were prematurity $(87,89.7 \%)$, respiratory distress $(70,70.2 \%)$, heart disease $(16,16.5 \%)$, sepsis $(15,15.5 \%)$, gastrointestinal tract disorders $(09 ; 9.7 \%)$ and electrolyte disturbances (5, $5.2 \%)$. There was no statistically significant difference between the infants with multiple or single therapy regarding clinical diagnoses $(p>0.05)$.

Table 1. Characterization of neonates undergoing epicutaneous catheter insertion according to the type of intravenous therapy. São Paulo, 2010-2011

\begin{tabular}{|c|c|c|c|c|c|}
\hline \multirow{3}{*}{$\begin{array}{l}\text { Demogra- } \\
\text { phic and } \\
\text { anthro- } \\
\text { pometric } \\
\text { variables }\end{array}$} & \multicolumn{4}{|c|}{ Intravenous Therapy } & \multirow{3}{*}{$\begin{array}{c}P \\
\text { va- } \\
\text { lue }\end{array}$} \\
\hline & \multicolumn{2}{|c|}{$\begin{array}{c}\text { Multiple } \\
(\mathrm{N}=82)\end{array}$} & \multicolumn{2}{|c|}{$\begin{array}{l}\text { Single } \\
(\mathrm{N}=15)\end{array}$} & \\
\hline & $\begin{array}{l}\text { Ave- } \\
\text { rage }\end{array}$ & SD & $\begin{array}{l}\text { Ave- } \\
\text { rage }\end{array}$ & SD & \\
\hline $\begin{array}{l}\text { Corrected } \\
\text { gestational } \\
\text { age (weeks) }\end{array}$ & 33.4 & 5 & 35.2 & 3.8 & 0.2 \\
\hline Days of life & 10.1 & 21 & 3.6 & 4.3 & 0.23 \\
\hline $\begin{array}{l}\text { Weight (gra- } \\
\mathrm{ms} \text { ) }\end{array}$ & 1691.1 & 864.5 & 1901.9 & 799.1 & 0.23 \\
\hline
\end{tabular}

Source: Authors' contribution

Considering the body segment associated with the insertion of the PICC, 79 (81.4\%) catheters were inserted through the veins of upper limbs, 13 (13.4\%) in veins of lower limbs and $5(5.1 \%)$ through the veins of the cervical or cephalic region. No differences were observed between groups with respect to the PICC installation segment $(p=0.8)$. The position of the tip of the PICC was central in most procedures $(85,86.7 \%)$, with no statistically significant difference between groups with multiple IV therapy or not $(p=1.0)$. In general, the clinical characteristics of newborns and epicutaneous catheter insertion procedures in the groups indicated for multiple and single infusion therapy were homogeneous.

The incidence of non-elective removal in the sample was $35.1 \%$ (34 catheters). This incidence was not significantly different in terms of the type of intravenous therapy, but it was almost $10 \%$ higher in catheters receiving multiple infusion. 
Table 2. Intravenous therapy type and incidence of non-elective removal of epicutaneous catheter. São Paulo, 2010-2011

\begin{tabular}{|c|c|c|c|c|c|c|}
\hline \multirow{3}{*}{$\begin{array}{c}\text { Non- } \\
\text {-elective } \\
\text { removal } \\
\text { incidence }\end{array}$} & \multicolumn{4}{|c|}{ Terapia infusional } & \multirow{3}{*}{$\begin{array}{c}P \\
\text { va- } \\
\text { lue }\end{array}$} & \multirow{3}{*}{$\begin{array}{l}\text { RR } \\
\text { [IC] }\end{array}$} \\
\hline & \multicolumn{2}{|c|}{$\begin{array}{c}\text { Multiple } \\
(n=82)\end{array}$} & \multicolumn{2}{|c|}{$\begin{array}{c}\text { Single } \\
(N=15)\end{array}$} & & \\
\hline & $N$ & $\%$ & $N$ & $\%$ & & \\
\hline & & & & & & 1.15 \\
\hline Yes & 30 & 36.5 & 4 & 26.7 & 0.33 & $\begin{array}{r}{[0.81-} \\
1.63]\end{array}$ \\
\hline No & 52 & 63.4 & 11 & 73.3 & & \\
\hline
\end{tabular}

Source: Authors' personal file

As for intravenous solutions that led to the installation of the PICC in neonates, it was observed that most of the single IV therapy PICCs were used for parenteral administration (40\%), antibiotics (20\%), serum (33.3\%) and phenobarbital (6.7\%). The catheters indicated for multiple intravenous therapy had greater indication for the infusion of the combination of antibiotics and parenteral nutrition (31.7\%), antibiotics and serum (29.3\%), antibiotics, vasoactive drugs and parenteral nutrition $(8.5 \%)$, antibiotics, vasoactive drugs and serum $(7.3 \%)$ and other solutions.

Regarding the complications that led to the non-elective removal of epicutaneous catheters, we observed that the most common ones were obstruction (26.5\%) and suspected infection (26.5\%). The ratio of the intravenous therapy and the complications leading to non-elective removal of the 34 catheters in the cohort of newborns can be found in Table 3 .

The average time the catheters remained installed was 11.1 days. In the single intravenous therapy group this period was of 11.4 days (SD: 13), while in the multiple IV therapy group it was of 11.1 (SD: 10.8) days. There was no statistically significant difference between groups regarding the average duration ( $p=$ 0.9).
Table 3. Intravenous therapy and complications on epicutaneous catheter. São Paulo, 2010-2011

\begin{tabular}{|c|c|c|c|c|c|}
\hline \multirow{3}{*}{ Complication } & \multicolumn{4}{|c|}{ Intravenous therapy } & \multirow{3}{*}{$\begin{array}{c}P \\
\text { va- } \\
\text { lue }\end{array}$} \\
\hline & \multicolumn{2}{|c|}{$\begin{array}{l}\text { Multiple } \\
(n=30)\end{array}$} & \multicolumn{2}{|c|}{$\begin{array}{l}\text { Single } \\
(N=4)\end{array}$} & \\
\hline & $\mathbf{N}$ & $\%$ & $\mathbf{N}$ & $\%$ & \\
\hline Obstruction & 8 & 26.7 & 1 & 25 & \\
\hline Rupture & 7 & 23.3 & 1 & 25 & \\
\hline $\begin{array}{l}\text { Catheter related } \\
\text { infection }\end{array}$ & 8 & 26.7 & 1 & 25 & \\
\hline Limb edema & 3 & 10 & 0 & - & 1.83 \\
\hline Extravasation & 2 & 6.7 & 0 & - & \\
\hline $\begin{array}{l}\text { Accidental dislod- } \\
\text { gement }\end{array}$ & 2 & 6.7 & 1 & 25 & \\
\hline
\end{tabular}

Source: Authors' personal file

\section{DISCUSSION}

Technological advances have contributed to the increased survival of premature and critically ill newborns admitted to the NICU. However, this population requires vascular access to facilitate the safe administration of prescribed infusion therapy. Therefore, nursing professionals are in constant search for ways of improvement in terms of their professional skills, as well as new technologies related to the material, design, number of lumens, safety and effectiveness of the appropriate vascular devices for critically ill neonates.

Regarding the material, design and number of lumen, PICCs available for the neonatal population can be made of silicone or polyurethane in gauges $1.0 \mathrm{Fr}$ to $3.0 \mathrm{Fr}$, and can be either one lumen or two lumens ${ }^{(2)}$. Polyurethane catheters have stronger walls, allowing the production of a small diameter catheter and the possibility of increased flow compared to catheters made of silicone ${ }^{(8)}$. The use of the smallest diameter and most redu- 
ced possible number of lumens according to the needs of the patient ${ }^{(1)}$ is recommended. Therefore, because of the different types of devices available, the choice of a vascular device that meets more appropriately the needs of each individual, is still a practice that requires evidence of its benefit.

The results of this research showed that silicone and single lumen PICCs were mainly used for the administration of antibiotics, serum and parenteral nutrition. Similar results were found in a randomized clinical trial conducted in a tertiary hospital in Sweden that sought to compare epicutaneous catheters to peripheral catheters. Of the 60 participants, 31 received the $5-\mathrm{Fr}$ single-lumen silicone PICC and 29 received the 18-gauge peripheral needled polyurethane catheter. In this study, the main indications for PICC were antibiotic therapy (61.3\%) followed by serum therapy $(19.4 \%)^{(10)}$.

The incidence of non-elective removal in this study was $35.1 \%$. Similar results were found in a retrospective study that analyzed 104 silicone single lumen 1.9 Fr PICCs installed in newborns admitted to the NICU in Beijing, where non-elective removal incidence was $31.73 \%^{(11)}$. Corroborating these findings, a cohort study with retrospective data collection analyzed the complications from 808 silicone single lumen 1.9 Fr PICCs installed in very underweight birth neonates in Taiwan, and found a complication incidence rate of $45.5 \%{ }^{(12)}$.

The results of this study suggest that there has been an increase in the risk of non-elective removal for single lumen PICCs that have been installed for multiple intravenous therapy, which is only a $15 \%$ greater risk (RR: 1.15). This increased risk of non-elective removal of catheters used for multiple infusions may be related to the formation of precipi- tation originated from parenteral nutrition, acid drugs, and inadequate permeabilization before and after drug administration ${ }^{(2)}$.

Regarding the incidence of complications that led to non-elective catheter removal, the results of this study indicate that this occurred in $26.7 \%$ of catheters receiving single infusion therapy, and in $36.6 \%$ of the catheters indicated for multiple therapy. Similar results were found in a study that aimed to examine the frequency and types of complications in 610 PICCs installed for administration of antibiotics in children. The complication rate was $16.2 / 1000$ catheter-days in the catheters used to administer up to four daily doses of antibiotics, and 23.6/1000 catheter-days in those used for more than four doses. The relative risk of complication was 1.45 times greater in terms of the catheters used to administer more than four daily doses of antibiotics ${ }^{(13)}$.

Regarding the complications that led to the non-elective removal of the catheters, limb edema and extravasation occurred only with the PICCs used for multiple IV therapy. The incidence of these complications was low considering all of catheters, i.e., 3.1\% and $2.1 \%$, respectively. The PICC-related edema is caused by poor circulation and venous congestion, with an incidence of $2.9 \%$ in an international study involving infants with PICC(11). On the other hand, leakage and rupture led to the removal of $15.3 \%$ of the 294 catheters inserted in newborns in a NICU in the United Kingdom ${ }^{(14)}$.

In general, in this research, most of the catheters were removed electively, independent of the intravenous therapy that justified their inclusion and had a similar dwell time. However, the complications that occurred most frequently among the catheters non-electively removed were obstruction in 9 
(9.3\%) PICCs, and suspected bloodstream infection related to the catheter also in 9 (9.3\%) PICCs. Similar findings were found in a descriptive study that aimed to identify adverse events related to central venous catheters in hospitalized newborns, showing that the PICC obstruction occurred in 19.44\% of 216 catheters inserted, and suspected infection in $2.8 \%{ }^{(15)}$.

Since mechanical and infectious complications can be preventable, early detection and promptly treatment, some modifications of nursing practice could be beneficial in reducing the non-elective removal of PICC, and improving the quality of care provided. To prevent obstruction, studies have shown that the prophylactic use of heparin allows newborns with PICC to finalize intravenous treatment with lower rates of obstruction ${ }^{(16)}$. Other preventive strategies against obstruction and rupture include permeabilizing catheters with saline solution before and after drug administration, and the use of syringes of at least $10 \mathrm{ml}$ and avoid the use of restrictive dressing ${ }^{(2)}$. To prevent catheter-related infection, the adoption of proper aseptic technique for insertion, the development of guidelines for the care of the site of catheter insertion and its maintenance and early removal, and conducting permanent education programs are recommended for health teams ${ }^{(17)}$.

The early detection of complications depends on the frequent monitoring of early signs such as resistance to the infusion ${ }^{(2)}$, the appearance of signs of inflammation ${ }^{(16)}$, alterations in laboratory tests ${ }^{(2)}$ and the clinical worsening of the neonate with no other apparent reason $^{(2)}$. Prompt treatment of complications often involves discontinuing the use of the catheter, using compresses to relieve pain and tissue damage, elevation of the affected limb and the use of medicines depending on the complication and institutional protocols. Finally, the quality of care for patients with this device is directly related to controlling the risk of infection, in which the efforts of the entire health care team must be applied in order to facilitate the implementation of evidence that guides safe clinical practice ${ }^{(18)}$.

Although this study examined a cohort of neonates undergoing the installation of 97 PICCs, some limitations should be considered. Of the catheters not removed electively, $88.2 \%$ were inserted for multiple infusional therapy, and only $11.8 \%$ for single therapy. This proportion was less significant when it cames to calculating the sample size in the study. Moreover, as it is a single-center study, the results represent the use of PICC in one private hospital with a dedicated nursing staff. However, this study helped to bring evidence to the nurses in terms of choosing the type of epicutaneous catheter with regard to the newborn intravenous therapy prescribed. The results suggest that nurses can opt for single lumen epicutaneous catheters made of silicone, even for neonates receiving more than one type of intravenous solutions at health services which have only this type of PICC. However, it is necessary to invest in order to prevent the most frequent complications.

\section{CONCLUSION}

The incidence of non-elective removal in single lumen silicone catheters indicated for multiple infusion therapy was similar to the incidence of non-elective removal found in national and international literature. Complications such as limb edema and extravasation appeared only in catheters used for multiple infusion therapy. It is worth noting complications that have a higher incidence, 
such as obstruction and suspected infection that have a higher incidence in the literature as well. Such complications limit or reduce the useful time of the vascular device due to its removal before the end of the drug therapy. Given that these complications can be avoided, it is necessary to invest in professional training of the nursing staff to enhance the quality of care.

\section{REFERENCES}

1. Infusion Nurses Society. Infusion nursing standarts of practice. J Intraven Nurs 2011;34(1 Supl 1S):S1-S110.

2. Pettit J, Wyckoff MM. Peripherally inserted central catheters: guideline for practice [Internet]. 2007; National Association of Neonatal Nurses [cited 2011 Jan 15]. Available from: http:// www.nann.org/pdf/PICCGuidelines.pdf.

3. Wojnar DG, Beaman ML. Peripherally inserted central catheter: compliance with evidence-based indications for insertion in an inpatient setting. J Infusion Nursing 2013;36(4):291-296.

4. Conselho Federal de Enfermagem (Brasil). Resolução COFEN- 258/2001. Inserção de Cateter Periférico Central pelos Enfermeiros. [Internet]. 2001 [cited 2011 jan 24]; Available from: http://site.portalcofen.gov.br/node/4296.

5. Conselho Regional de Enfermagem de São Paulo (COREN-SP). Parecer COREN-SP 043/2013-CT PCRI n¹00.988. Passagem, cuidados e manutenção de PICC e cateterismo umbilical. [Internet]. São Paulo; 2013 [cited 2014 maio 20]. Available from:http://portal. corensp.gov.br/sites/default/files/parecer_coren_sp_2013_43.pdf

6. Costa P, Kimura AF, Vizzotto MPS, Castro TE, West A, Dorea E. Prevalence and reasons for non-elective removal of peripherally inserted central catheter in neonates. Rev Gau Enf 2012;33(3):126-33.

7. Lourenço AS, Ohara CVS. Conhecimento dos enfermeiros sobre a técnica de inserção do cateter central de inserção periférica em recém-nascidos. Rev. Latino-Am. Enfermagem 2010; 18(2):189-195.

8. Westergaard B, Classen V, Walther-Larsen S. Peripherally inserted central catheters in infants and children-indications, techniques, complications and clinical recommendations. Acta Anaesthesiol Scand 2012; 57(3):278-87. doi: 10.1111/aas.12024.

9. Paiva DE, Kimura AF, Costa P, Magalhães TEC, Toma E, Alves AMA. Complicações relacionadas ao tipo de cateter epicutâneo em uma coorte de neonatos. Online Braz J Nurs (Online) [internet]. 2013; Dec 2013. [Cited 2014 Maio 22] 12(4). Available from http://www.objnursing.uf.br/index. php/nursing/article/view/4071.http://dx.doi. org/10.5935/1676-4285.20134071

10. Periard D, Monney P, Waeber G, Zurkinden C, Mazzola L, Hayoz D, et al. Randomized controlled trial of peripherally inserted central catheters vs. peripheral catheters for middle duration in-hospital intravenous therapy. J Thromb Haemost 2008;6(8):1281-8. doi: 10.1111/j.1538-7836.2008.03053.x.

11. Liu Huili RN, Han Tongyan Han MD, Yueyin Zheng RN, Xiaomei Tong MD, Et al. Analysis of complication rates and reasons for nonelective removal of PICCs in neonatal intensive care unit preterm infants. J Infus Nurs 2009;32(4):336-340.

12. Tsai MH, Chu SM, Lien R, Huang HR, Wang JW, Chiang CC, et al. Complications associated with 2 different types of percutaneously inserted central venous catheters in very low birth weight infants. Infect Control Hosp Epidemiol 2011;32(3):258-266.

13. Barrier A, Williams DJ, Connelly M, Creech CB. Frequency of peripherally inserted central catheter complications in children. Pediatr Infect Dis J. 2012 May;31(5):519-21

14. Njere I, Islam S, Parish D, Kuna J, Keshtgar AS. Outcome of peripherally inserted central venous catheters in surgical and medical neonates. J Pediatr Surg 2011; 46(5):946-50. doi:10.1016/j.jpedsurg.2011.02.037

15. Franceschi AT, Cunha MLC. Adverse events related to the use of central venous catheters in hospitalized newborns. Rev. Latino-Am Enferm. 2010;18(2):57-63. 
16. Johann DA, De Lazzari LS, Pedrolo E, Mingorance $P$, de Almeida TQ, Danski MT. Peripherally inserted central catheter care in neonates: an integrative literature review]. Rev Esc Enf USP 2012; 46(6):1503-11.

17. Rosado V, Romanelli RMC, Camargos PAM. Risk factors and preventive measures for catheter-related bloodstream infections. J Ped 2011; 87(6):469-77.

18. Andrade MR, Silva HG, Oliveira BGRB, Cruz ICF. Risk of infection in central venous catheter: review study to nursing care. Online Braz J Nurs (Online) [internet]. 2012; Nov 2010. [Cited 2013 Sep 30] 9(2). Available from: http://www.objnursing.uff.br/index.php/ nursing/article/view/3109. doi:http://dx.doi. org/10.5935/1676-4285.20103109.

\section{Authors' contribution:}

'Planning of the study design, collection and analysis of data, elaboration of the manuscript.

"Processing and analysis of data, elaboration of the manuscript.

III Planning of the study design, data analysis, and elaboration of the manuscript.
All authors participated in the phases of this publication in one or more of the following steps, in According to the recommendations of the International Committee of Medical Journal Editors (ICMJE, 2013): (a) substantial involvement in the planning or preparation of the manuscript or in the collection, analysis or interpretation of data; (b) preparation of the manuscript or conducting critical revision of intellectual content; (c) approval of the versión submitted of this manuscript. All authors declare for the appropriate purposes that the responsibilities related to all aspects of the manuscript submitted to OBJN are yours. They ensure that issues related to the accuracy or integrity of any part of the article were properly investigated and resolved. Therefore, they exempt the OBJN of any participation whatsoever in any imbroglios concerning the content under consideration. All authors declare that they have no conflict of interest of financial or personal nature concerning this manuscript which may influence the writing and/or interpretation of the findings. This statement has been digitally signed by all authors as recommended by the ICMJE, whose model is available in http://www. objnursing.uff.br/normas/DUDE_eng_13-06-2013.pdf

Received: 09/30/2013

Revised: 05/19/2014

Approved: 05/26/2014 